\title{
AVO investigation of the Ben Nevis reservoir at the Hebron asset
}

\author{
Andrew J. Royle, John D. Logel ${ }^{1}$, and Laurence R. Lines
}

\begin{abstract}
This paper investigates the amplitude variation with offset (AVO) behavior at the Ben Nevis reservoir zone in an attempt to predict API oil gravity variations. Intercept, gradient, fluid factor, and density reflectivity attribute volumes were extracted to observe the AVO effects at the reservoir zone. These attributes isolated the oil zones associated with the Ben Nevis reservoir and showed differences between the adjacent fault block reservoir zones. Detailed crossplotting at the oil bearing well locations isolated anomalous zones associated with the response at the top of the reservoir. In comparison the highlighted anomalous crossplot zones showed differences for the varying oil gravity.
\end{abstract}

\section{INTRODUCTION}

The Hebron asset is comprised of Hebron, West Ben Nevis, and the Ben Nevis fields. This prospect is located in the southern portion of the Jeanne d'Arc Basin, approximately 350 kilometers from St. John's, Newfoundland (Figure 1). Significant discovery licenses covering this asset were awarded in the mid 1980's based on four exploratory wells over an area of approximately 36 square kilometers.

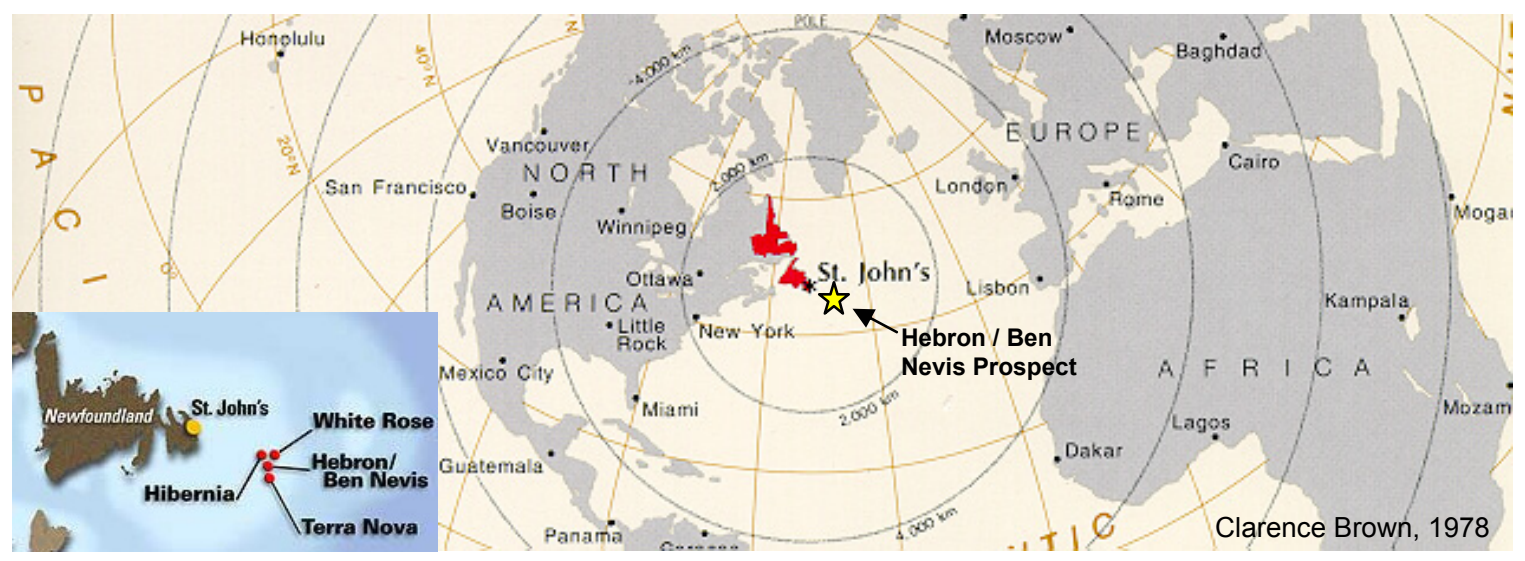

FIG.1: Hebron / Ben Nevis location map

Oil in place potential for the asset including un-drilled fault blocks is estimated to exceed 2 billion barrels. The $\mathrm{CNOPB}^{2}$ states that there are about 400 million barrels of recoverable oil, based on what has been already drilled, making Hebron the second largest field in the Jeanne d'Arc Basin after Hibernia. The upper Ben Nevis horizon encountered significant volumes of crude with gravities in the range of 19 to 21 degree API. Oil is usually classified as heavy if it has API gravities of 20 degrees or less. Therefore, the oil encountered in the Ben Nevis is still not as dense as water. The density of this oil however presents several production challenges and may require special

\footnotetext{
${ }^{1}$ Anadarko Canada Corporation, Calgary, Alberta, Canada.

${ }^{2}$ Canada-Newfoundland Offshore Petroleum Board
} 
processing equipment. The Hibernia and Jeanne d'Arc horizons encountered marginal volumes of lighter gravity crude. The Hibernia formation encountered 29 degree gravity oil while the Jeanne d'Arc encountered highly variable gravities from 24 to 36 degree gravity oil, the higher of which are similar to those of the Hibernia oil field (Figure 2).

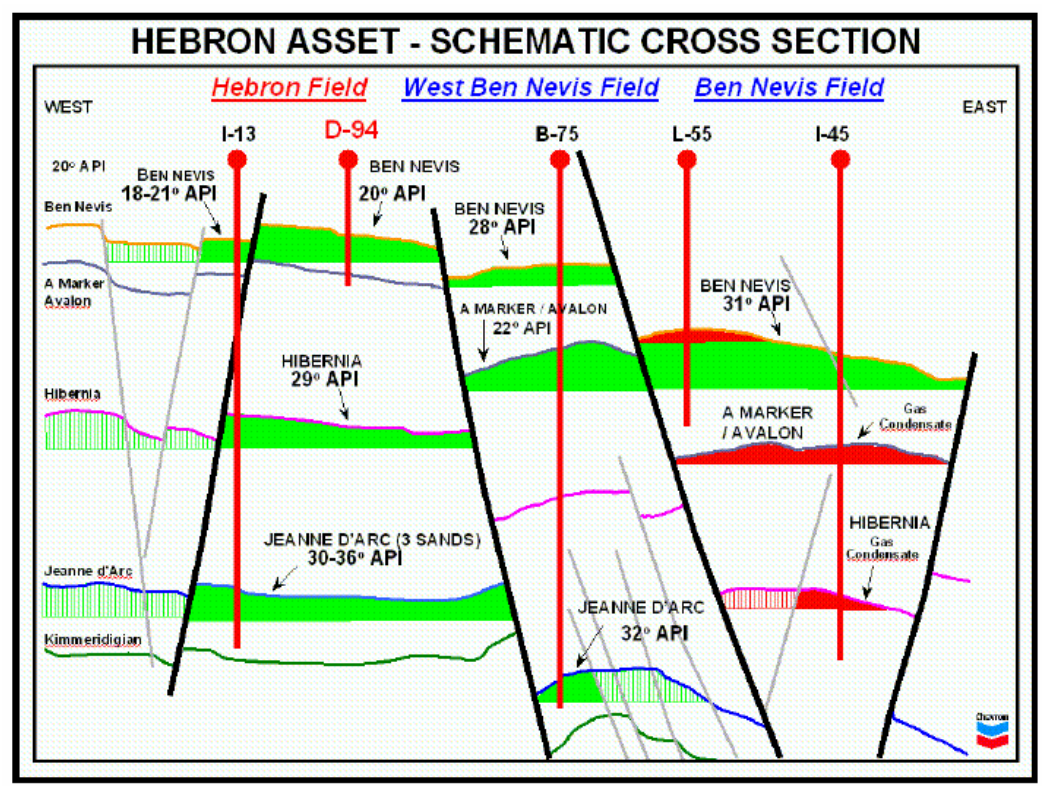

FIG.2. Schematic cross section of Hebron /Ben Nevis asset (after Provais, 2000)

AVO methods have been used to predict hydrocarbons in clastic reservoirs offshore eastern Canada. AVO is quite useful in the fact that it has the potential to reduce the drilling risk, which is valuable for costly offshore drilling. This method can be a valuable exploration tool but traditionally it cannot distinguish between commercial and noncommercial (low hydrocarbon saturation) reservoir zones. This is because the Pwave velocity is very sensitive to the presence of a hydrocarbon in the pore space of a rock even at very low saturation of hydrocarbons. The S-wave velocity and density, however, are not as sensitive to low hydrocarbon saturations in the pore spaces. Using two-parameter AVO equations the P-wave velocity is always linked to the shear wave velocity or density and therefore there is no bias at lower hydrocarbon saturations. Lines (1999), Kelly et al. (2001), Downton (2001) and others have explored a three-parameter AVO extraction in order to get more information from $\mathrm{P}$-wave seismic data in an attempt to isolate rock property contrasts. This method may prove to be an interesting approach at the Hebron / Ben Nevis prospect in an attempt to differentiate between the varying oil gravities.

The oil in the Ben Nevis zone has a specific gravity ranging from approximately 0.84 to 0.95 . Therefore, it maybe possible to distinguish between the different gravity hydrocarbons. The Ben Nevis has a gas cap in the structural high regions of the eastern fault blocks; this may aid in discriminating some of the reservoir zones and the hydrocarbon boundaries. 


\section{METHODS}

\section{AVO methodology}

\section{Shuey approximation}

Shuey's approximation of the Zoeppritz' equations shows the relationship of reflection coefficient versus angle of incidence to changes in impedance and Poisson's ratio. Shuey (1985) approximates the Zoeppritz' equations from Aki and Richards (1980) by eliminating the properties $V_{S}$ and $\Delta V_{S}$ in the favour of $\sigma$ and $\Delta \sigma$. Shuey's approximation is as follows:

$$
R(\theta)=R_{O}+\left[A_{O} R_{O}+\frac{\Delta \sigma}{(1-\sigma)^{2}}\right] \sin ^{2} \theta+\frac{1}{2} \frac{\Delta V_{P}}{V_{P}}\left(\tan ^{2} \theta-\sin ^{2} \theta\right),
$$

where $R_{O}$ is the normal incidence reflection coefficient, $A_{O}$ is the normal incidence amplitude, $\sigma$ is Poisson's ratio, $\Delta \sigma$ is the difference in Poisson's ratio $\left(\sigma_{2}-\sigma_{1}\right)$, and $\theta$ is the average angle of incidence measured from the vertical $\left[\left(\theta_{1}+\theta_{2}\right) / 2\right]$. This approximation is commonly used in AVO as it contains three terms separating the normal incidence, small angle (to about 30 degrees), and large angle contributions to the total reflection coefficient at any given angle (Allen \& Peddy, 1993). Shuey's approximation gives a relatively simple relationship between rock properties (Poisson's ratio) and the variation in reflection coefficients, and stresses the importance of Poisson's ratio as the primary determinant of the AVO response of a reflection. Shuey's approximation (1) can be simplified even further by omitting the higher order contribution:

$$
R(\theta)=R_{0}+G \sin ^{2} \theta,
$$

where, $R_{0}$ is the normal incident P-wave reflectivity or "intercept" and $G$ is the "gradient" term. The intercept represents the theoretical zero-offset response; this response will show "bright spots" but does not show any AVO effect. The gradient by definition is the rate of change of the amplitudes at each time sample as a function of incidence angle on a CDP gather. This value should contain the entire AVO effect. The intercept and gradient terms from this approximation can be easily obtained through linear regression.

\section{Fatti et al. approximation}

Fatti et al. extend the Smith and Gidlow (1987) method to include the density term. Their starting point is the linearized approximated form of the Zoeppritz equation from Aki and Richards (1980):

$$
R=\frac{1}{2}\left(\frac{\Delta V_{P}}{V_{P}}+\frac{\Delta \rho}{\rho}\right)-2\left(\frac{V_{S}}{V_{P}}\right)^{2}\left(2 \frac{\Delta V_{S}}{V_{S}}+\frac{\Delta \rho}{\rho}\right) \sin ^{2} \theta+\frac{1}{2}\left(\frac{\Delta V_{P}}{V_{P}}\right) \tan ^{2} \theta,
$$


where $R=\mathrm{P}$-wave reflection coefficient, $V_{P}=$ average $P$-wave velocity, $V_{S}=$ average $S$-wave velocity, $\rho=$ average density, and $\theta=$ average of $\theta_{1}$ and $\theta_{2}$.

Equation (3) is accurate to angles of incidence around 35 degrees for typical velocity and density contrasts. Like Smith and Gidlow (1987), they assume $\Delta V_{P} / V_{P}, \Delta V_{S} / V_{S}$, and $\Delta \rho / \rho$ are sufficiently small that the second order terms may be ignored and $\theta$ does not approach critical angle or 90 degrees. They state that if Gardner's relationship does not hold, equation (3) can be written in terms of P-wave and S-wave acoustic impedances:

$$
\begin{aligned}
& I_{P}=\rho V_{P}=P \text {-wave acoustic impedance, } \\
& I_{S}=\rho V_{S}=S-\text { wave acoustic impedance, } \\
& \frac{1}{2} \frac{\Delta I_{P}}{I_{P}}=\frac{1}{2}\left(\frac{\Delta V_{P}}{V_{P}}+\frac{\Delta \rho}{\rho}\right)=\text { zero offset } P \text {-wave reflection coefficient, and } \\
& \frac{1}{2} \frac{\Delta I_{S}}{I_{S}}=\frac{1}{2}\left(\frac{\Delta V_{S}}{V_{S}}+\frac{\Delta \rho}{\rho}\right)=\text { zero offset } S \text {-wave reflection coefficient. }
\end{aligned}
$$

Equation (3) now becomes:

$R=\frac{1}{2} \frac{\Delta I_{P}}{I_{P}}\left(1+\tan ^{2} \theta\right)-4\left(\frac{V_{S}}{V_{P}}\right)^{2}\left(\frac{\Delta I_{S}}{I_{S}}\right) \sin ^{2} \theta-\left[\frac{1}{2}\left(\frac{\Delta \rho}{\rho}\right) \tan ^{2} \theta-2\left(\frac{V_{S}}{V_{P}}\right)^{2}\left(\frac{\Delta \rho}{\rho}\right) \sin ^{2} \theta\right]$

The third term in (6) is small for angles of incidence less than 35 degrees and $V_{S} / V_{P}$ ratios between 0.1 and 2.0 (Poisson's Ratio between 0.1 and 0.33) (Fatti et al., 1994). Equation (6) now simplifies to:

$$
R=\frac{1}{2} \frac{\Delta I_{P}}{I_{P}}\left(1+\tan ^{2} \theta\right)-4\left(\frac{V_{S}}{V_{P}}\right)^{2}\left(\frac{\Delta I_{S}}{I_{S}}\right) \sin ^{2} \theta
$$

Once a relationship between offset distance $(x)$ and angle of incidence $(\theta)$, a value for $\left(V_{S} / V_{P}\right)$ has been designated, and ray tracing has been performed then least squares curve fitting is done to fit equation (7) to the $P$-wave reflection amplitudes from real data CMP gathers to estimate $\Delta I_{P} / I_{P}$ and $\Delta I_{S} / I_{S}$. Now, the unknowns $\Delta I_{P} / I_{P}$ and $\Delta I_{S} / I_{S}$ can be solved at the boundary. The output of the weighted stacks will be traces representing $\Delta I_{P} / I_{P}$, or $P$-wave impedance reflectivity, and $\Delta I_{S} / I_{S}$, or $S$-wave impedance reflectivity, both with the normal time scale of the seismogram.

\section{Fluid Factor}

The "fluid factor" concept introduced by Smith and Gidlow (1987) attempts to highlight gas-bearing sandstones. The Fluid Factor is a scalar quantity that is designed to be low amplitude for all reflectors in a clastic sedimentary sequence except for rocks that lie off the "mudrock line". In the absence of carbonates and igneous rocks, high amplitude reflections on fluid factor traces would be expected to represent gas-saturated 
sandstones. Water saturated sandstones, shales, and siltstones should fall approximately on the mudrock line. Gas saturated sandstones on the other hand have lower P-wave velocities and slightly higher S-wave velocities and therefore fall of the mudrock line. Taking the derivative of Castagna et al. (1985) mudrock relationship, gives:

$$
\Delta V_{P}=1.16 \Delta V_{S}
$$

Solving for reflectivities gives:

$$
\begin{gathered}
\left(\frac{\Delta V_{P}}{2 V_{P}}\right)=1.16\left(\frac{V_{S}}{V_{P}}\right)\left(\frac{\Delta V_{S}}{2 V_{S}}\right), \\
\text { i.e., } R_{P}=1.16\left(\frac{V_{S}}{V_{P}}\right) R_{S},
\end{gathered}
$$

where $R_{P}$ is the zero-offset $\mathrm{P}$-wave reflection coefficient, and $R_{S}$ is the zero-offset $\mathrm{S}$-wave reflective coefficient.

Then the "fluid factor", $\Delta F$, can be defined as:

$$
\Delta F=R_{P}-1.16\left(\frac{V_{S}}{V_{P}}\right) R_{S} .
$$

If the layers above and below the boundary that produce a reflection lie on the mudrock line, then $\Delta F=0$. But if one of the layers lies on and the other off the mudrock line, then $\Delta F$ does not equal zero. Another approach to the "fluid factor" equation is that $\Delta F$ is the difference between the actual $\mathrm{P}$-wave reflection coefficient $R_{P}$ and the calculated $R_{P}$ for the same sandstone in a water saturated state. The calculated $R_{P}$ is determined from the S-wave reflection coefficient $\left(R_{S}\right)$ using the local mudrock line relationship giving the equation:

$$
\Delta F(t)=R_{P}(t)-g(t) R_{S}(t),
$$

where $t$ is the two-way time, $\Delta F(t)$ is the fluid factor trace, $R_{P}$ is the P-wave reflectivity trace, $R_{S}$ is the S-wave reflectivity trace, $g(t)=M\left(V_{S} / V_{P}\right)$ is a slowly time-varying gain function (geo-gain term), and $M$ is the slope of the mudrock line, which can be an appropriate local value rather than the global mudrock trend (Castagna et al., 1985)

\section{Three-term AVO extraction}

In this paper a linearized approach to the Aki-Richards approximation (1980) is used for the 3-term analysis. The outputs of the approximation are intercept (A), gradient (B), and curvature $(\mathrm{C})$. The intercept and gradient terms should be similar to what is extracted using the two-term extraction. These attribute volumes can be further arranged into Pwave contrast $\left(\Delta V_{P} / V_{P}\right), \mathrm{S}$-wave velocity contrast $\left(\Delta V_{S} / V_{S}\right)$, and density contrast $(\Delta \rho / \rho)$ by further manipulation. These volumes give insight on the key rock property contrasts. 
In order to obtain accurate results from 3-term AVO approximations, a good angle distribution is needed ( $\sim 45$ degrees) especially for relevant input for the third term.

The Aki and Richards (1980) equation:

$$
R(\theta)=A+B \sin ^{2}(\theta)+C \sin ^{2} \tan ^{2}(\theta),
$$

where $\mathrm{A}, \mathrm{B}$, and $\mathrm{C}$ are defined in terms of the rock property contrasts:

$$
\begin{aligned}
& A=\frac{1}{2} \frac{\Delta V_{P}}{V_{P}}+\frac{1}{2} \frac{\Delta \rho}{\rho}, \\
& B=\frac{1}{2} \frac{\Delta V_{P}}{V_{P}}-2\left(\frac{V_{S}}{V_{P}}\right)^{2}\left(2 \frac{\Delta V_{S}}{V_{S}}+\frac{\Delta \rho}{\rho}\right), \text { and } \\
& C=\frac{1}{2} \frac{\Delta V_{P}}{V_{P}} .
\end{aligned}
$$

Once $\mathrm{A}, \mathrm{B}$, and $\mathrm{C}$ attributes are acquired, they can be arranged to get $\mathrm{P}$-wave velocity reflectivity $\left(\Delta V_{P} / V_{P}\right)$, S-wave velocity reflectivity $\left(\Delta V_{S} / V_{S}\right)$, and density reflectivity $(\Delta \rho / \rho)$.

\section{DATA}

\section{Well data}

Seven wells have been drilled to this point defining the Hebron asset shown in Figure 3. The discovery well drilled into the prospect was the Mobil et al. I-45 well in 1980. Two phases of drilling to further delineate the prospect followed the I-45 well. The first phase occurred in the mid 1980s and the second phase occurred between 1999 and 2000. In 1981 the first of the delineation wells was drilled, the Mobil et al. I-13 which also encountered hydrocarbon accumulations. In 1985, the Petro-Canada et al. B-75 well was drilled to test the structurally high point between the I-45 and I-13 wells. The PetroCanada et al. H-71 well drilled in 1985 stepped out from the other wells to test lateral extent but encountered no significant hydrocarbon accumulations. After the first phase of drilling was completed the prospect was deemed uneconomic. After a progression of technology, establishment of infrastructure, and development of fields in the Jeanne d'Arc Basin the consideration for the second phase began. In early 1999, the PetroCanada et al. D-94 well was drilled and encountered significant quantities of oil $(\sim 1$ Billion STOOIP) in the Ben Nevis reservoir. The Chevron et al. L-55 well was drilled in 1999 to further evaluate the Ben Nevis reservoir adjacent to the I-45 discovery well. The last well was drilled in 2000; the Chevron et al. M-04 further tested the Hebron horst block. All the wells on the Hebron prospect contain a full suite of well-log data. The quality of the log data varied from fair for the 1980s wells, to good for the more recent wells. The M-04, D-94, and L-55 log suites include dipole sonic logs. Thorough petrophysical analysis of these logs has been done in house at ChevronTexaco providing key geologic tops and a comprehensive Multimin analysis. 


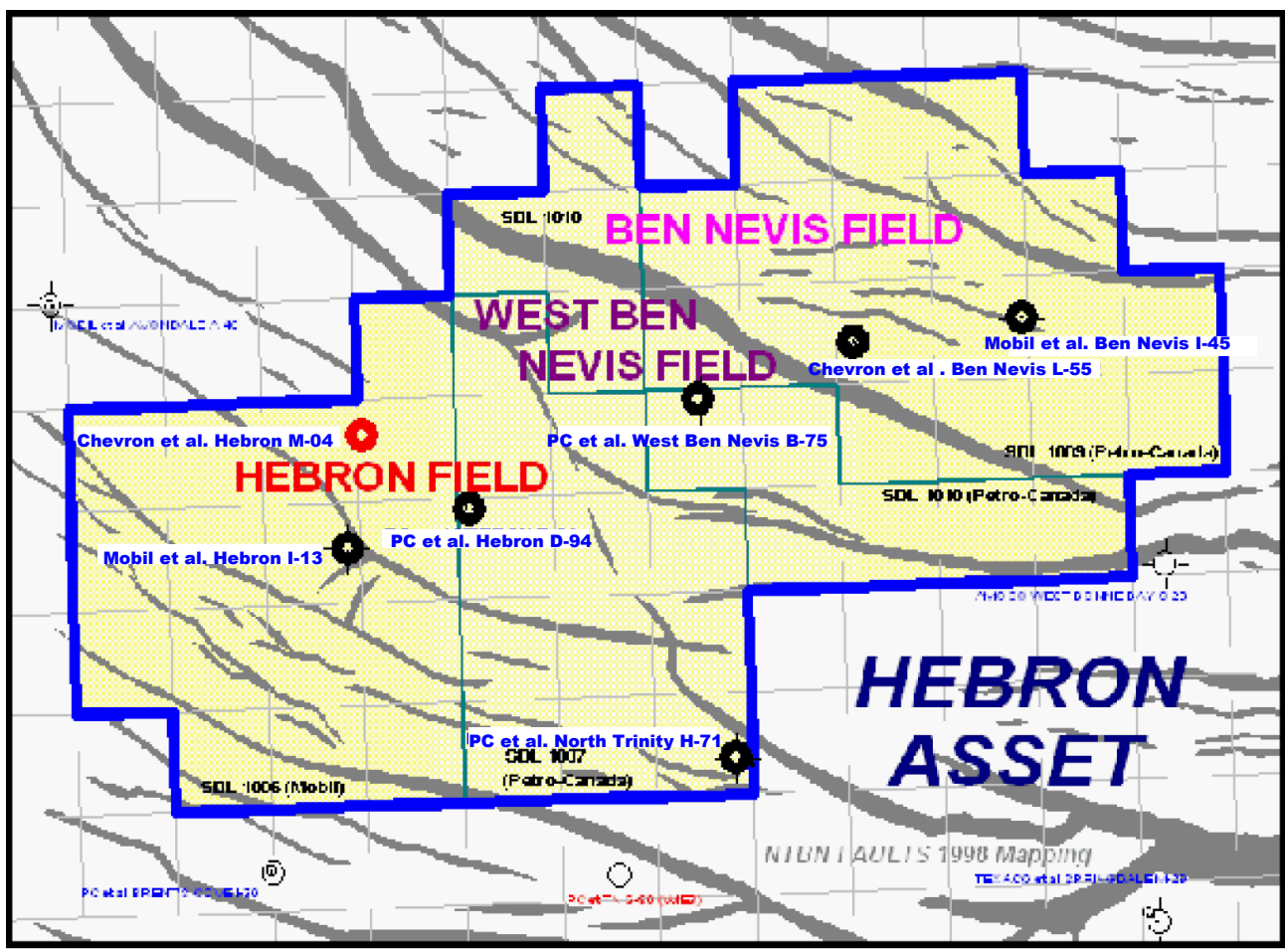

FIG.3. Hebron Asset map showing well locations

\section{Seismic data}

A 3D survey was acquired over the Cape Race, Hebron Ben Nevis, and Terra Nova licenses in the summer of 1997. This survey was acquired by PGS Exploration AS using the vessel $R / V$ Ramform Explorer. The survey consists of 93 lines each spaced $400 \mathrm{~m}$ apart with lengths from $11 \mathrm{~km}$ to almost $29 \mathrm{~km}$. A total of 2332 sail km were acquired and the survey covers over $700 \mathrm{~km}^{2}$. The Hebron/Ben Nevis portion of the survey consists of 28 shot lines with lengths varying from 27 to $29 \mathrm{~km}$. A total of about 800 sail $\mathrm{km}$ were acquired for Hebron/Ben Nevis. This portion of the survey covers about 316 $\mathrm{km}^{2}$. All of the lines were shot in an east-west orientation (88.16 degrees, NAD-83). A two airgun array was used with the airguns separated by $50 \mathrm{~m}$ and a shot pint interval of $25 \mathrm{~m}$. A total of eight streamers, each with a cable length of $4050 \mathrm{~m}$ at a depth of $8 \mathrm{~m}$ $(+/-1 \mathrm{~m})$, were employed. Streamer separation was $100 \mathrm{~m}$. There were 162 groups with an interval of $25 \mathrm{~m}$. The resulting nominal fold is $4100 \%$.

\section{INTERPRETATION AND ANALYSIS}

In this analysis a subset of the 3D volume covering the Hebron asset was pre-stack migrated in preparation for AVO analysis. The key horizon markers used for this analysis were provided by ChevronTexaco and Petro-Canada. The horizons used were the Petrel marker, top Ben Nevis, A-marker, and the B-marker. These horizons were used to constrain a velocity model for ray tracing, an initial low frequency model for post-stack inversion, and map generation of the extracted attribute volumes. The top Ben Nevis time structure map for the entire 3D survey is shown in Figure 4. This also shows 
the location of the cross section in Figure 2 and the dimensions of the pre-stack migrated volume.

Initially, all the wells on the 3D volume were correlated using extracted statistical wavelets. Each wavelet was extracted on a 20 by 20 trace region surrounding the well location and a time window encompassing the well length. As mentioned, these wells were then used to create a velocity model. This velocity model was used to ray trace the CDP gathers to achieve angle gathers for input into the AVO analysis.

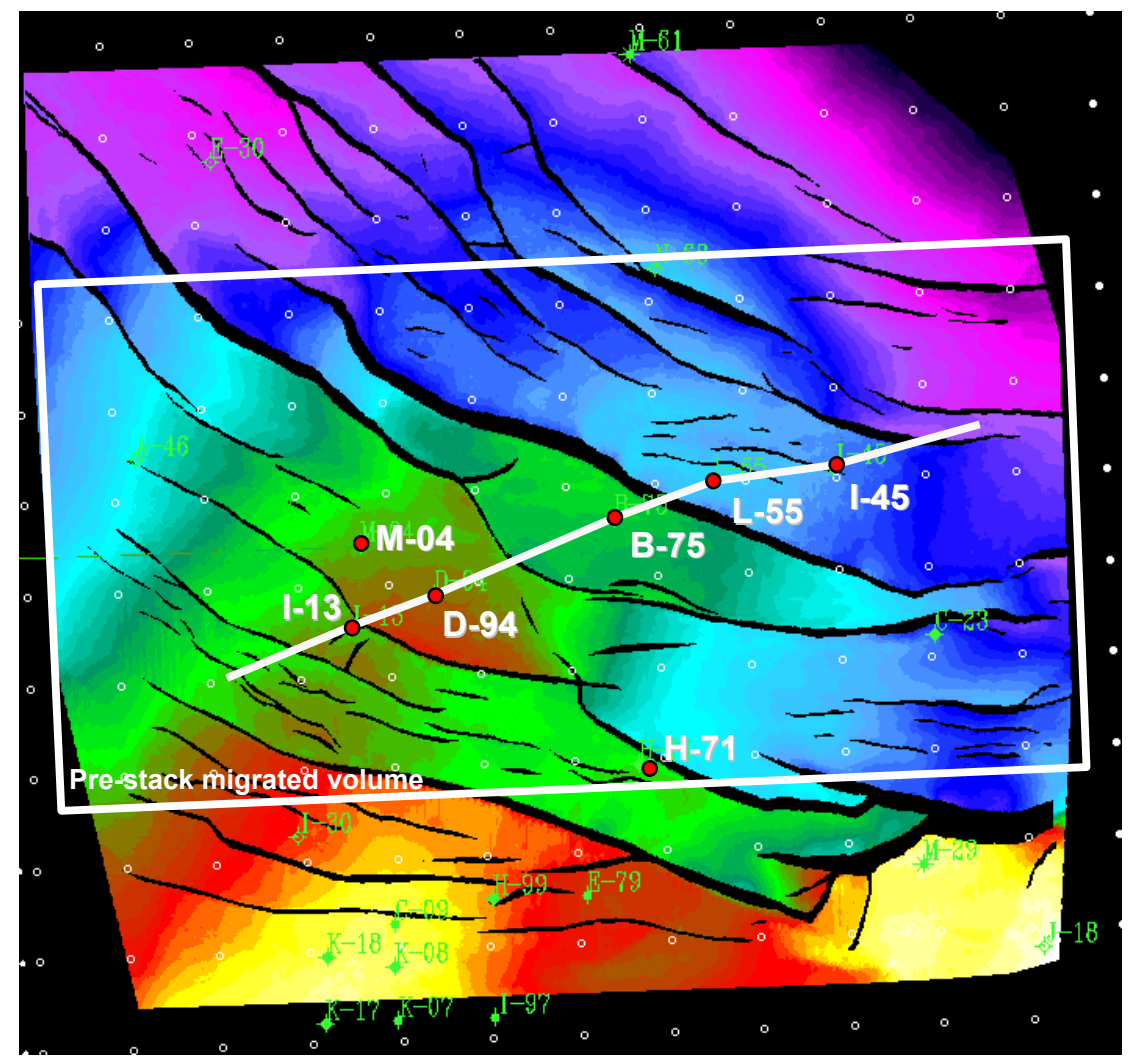

FIG.4. Top Ben Nevis time structure map

The reservoir quality in the Ben Nevis degrades from the higher regions in the west to the deeper regions in the east. The porosity decreases with depth and the P-wave velocity and density increase with depth. This also may influence the AVO response at the Ben Nevis zone. Ultimately, a method to extract the pore fluid information with the varying reservoir conditions is desired.

Prior to the application of the two- and three-term AVO approximations the response of the reflection coefficients with varying offset at the top of the zone of interest was investigated. This is shown in Figure 5 comparing the approximations used in this study. The black line represents the response of the exact Zoeppritz equations; the approximations are compared to this result for accuracy. The Shuey approximation is accurate to about 32 - 35 degrees. The Aki-Richards two-term approximation is accurate to about the same as the Shuey. The Aki-Richards three-term approximation almost overlays the exact Zoeppritz to about 60 degrees. It can be said for this study that the 
Shuey (two-term) approximation is good from approximately 30 - 35 degrees and the Aki-Richards (three-term) approximation can be theoretically used to 60 degrees. The second term (B) of the Aki-Richards contributes to about 32 degrees and the third term (C) from $32-80$ degrees. The two term Fatti et al. approximation contributes to about 36 degrees before it starts deviating from the Zoeppritz values. These values are taken into account when extracting the AVO attributes.

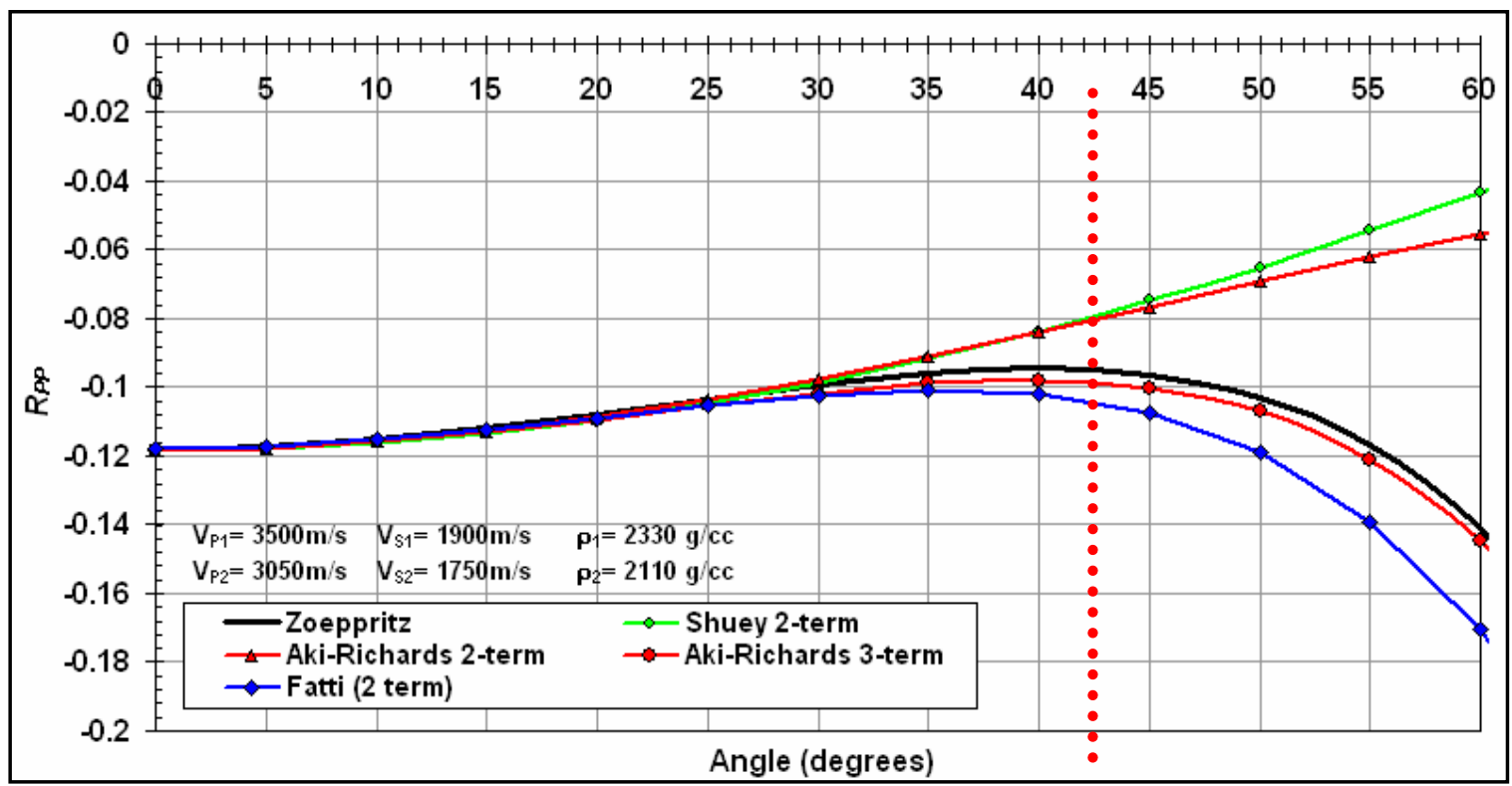

FIG.5. Comparison of approximations to the exact Zoeppritz at the top of the zone of interest

\section{Intercept and Gradient analysis}

Intercept $(A)$ and gradient $(B)$ volumes were created using Shuey's approximation of the Zoeppritz equations. The intercept attribute represents the theoretical zero-offset response. This will show amplitude effects such as "bright spots" but will not show any AVO effects. The gradient attribute shows the rate of change of the amplitudes on the CDP gather at each time sample as a function of angle incidence. This attribute should show the entire AVO effect.

A time slice taken through the top of the Ben Nevis zone was created and is shown in Figure 6. A distinct AVO anomaly can be seen across the whole asset. The anomaly is strongest in the B75 block followed by the D94 block. The L55 block shows a weak response, indicating the poorer reservoir quality compared to the others. The I13 well also shows a weak AVO response again degraded reservoir quality. These responses are expected - as mentioned the D94 block has the best reservoir quality but has 17 to 22 API oil. The B75 block has the second best quality and the oil is lighter ( 28 API), whereas the L55 block has poor reservoir quality with 31 API oil and a gas cap. The Ben Nevis zone in the L55 block is also 500 meters deeper than the other Ben Nevis zones. The porosity and permeability values are also greatly reduced. The I13 well also has high density oil ( 18-21 API) with a reduced porosity compared to the D94 block. A strong AVO anomaly up-dip in B75 block probably indicates the presence of a gas cap. 


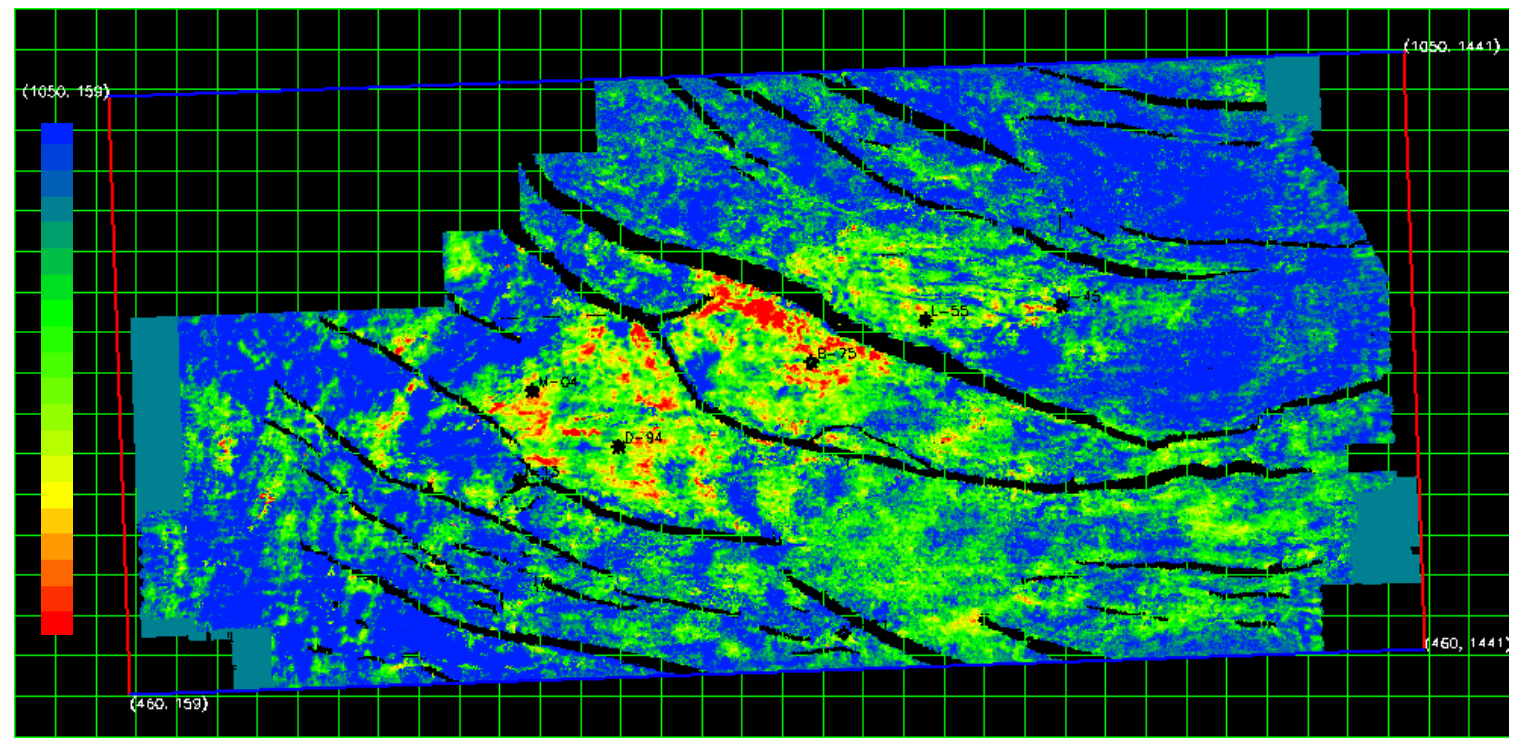

FIG.6. Gradient time slice at the top Ben Nevis horizon

Crossplotting of intercept (A) and gradient (B) data provides useful insight on the nature of the pore fluid. In an intercept versus gradient crossplot, brine-filled sandstones and shales should fall on a well-defined "background-trend". Outliers from this background trend may possibly indicate accumulations of hydrocarbons or lithologies with anomalous rock properties.
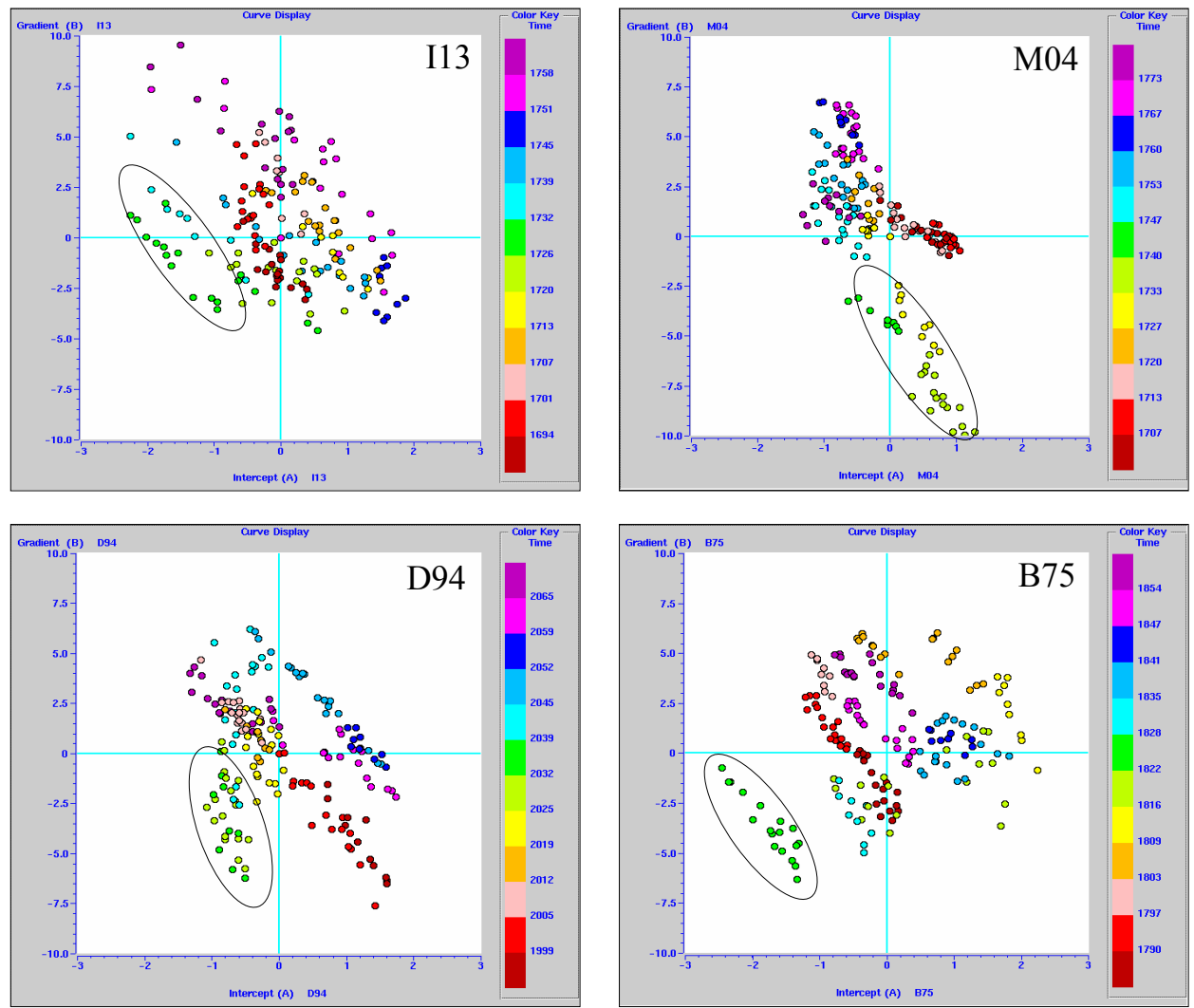

FIG.7. Intercept versus gradient crossplots at well locations on Hebron asset. 

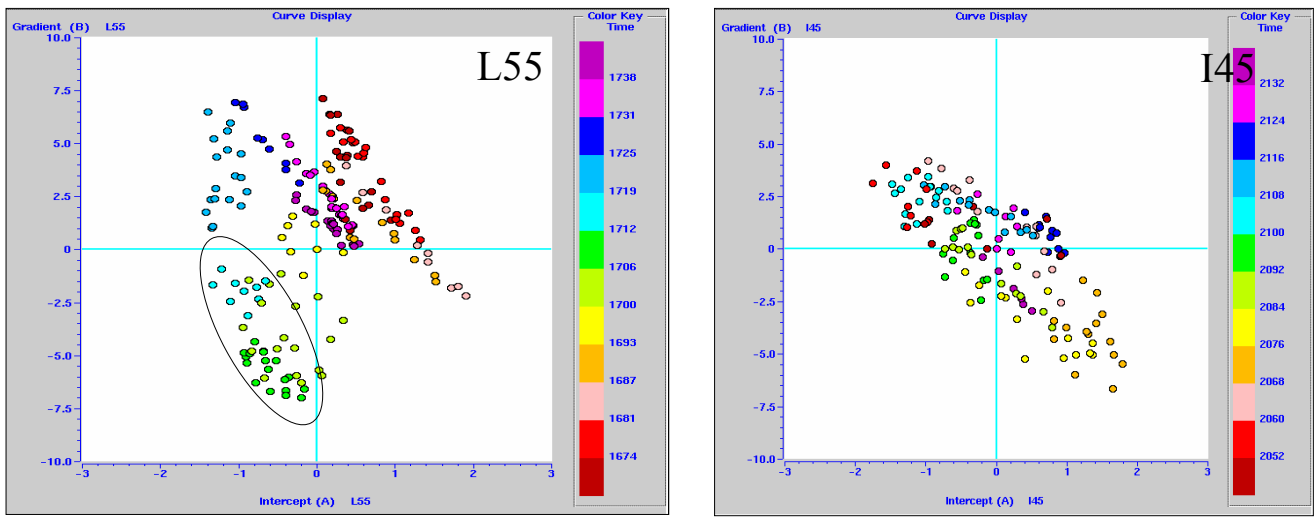

FIG.7. (continued) Intercept versus gradient crossplots at well locations on Hebron asset

The gradient and intercept volumes are crossplotted at each well location to compare the effects of the varying oil density across the asset. A 3 by 3 trace volume around the well is crossplotted with an $80 \mathrm{~ms}$ window centered on the Ben Nevis pick. These plots are shown in Figure 7. The top of the Ben Nevis zone is highlighted by the green ovals. All of the crossplots show deviations from the background trend with the exception of the I45 well. The I45 crossplot shows no anomalies and therefore represents a good background trend for comparison. A direct comparison of the anomalous zones is shown in Figure 8.

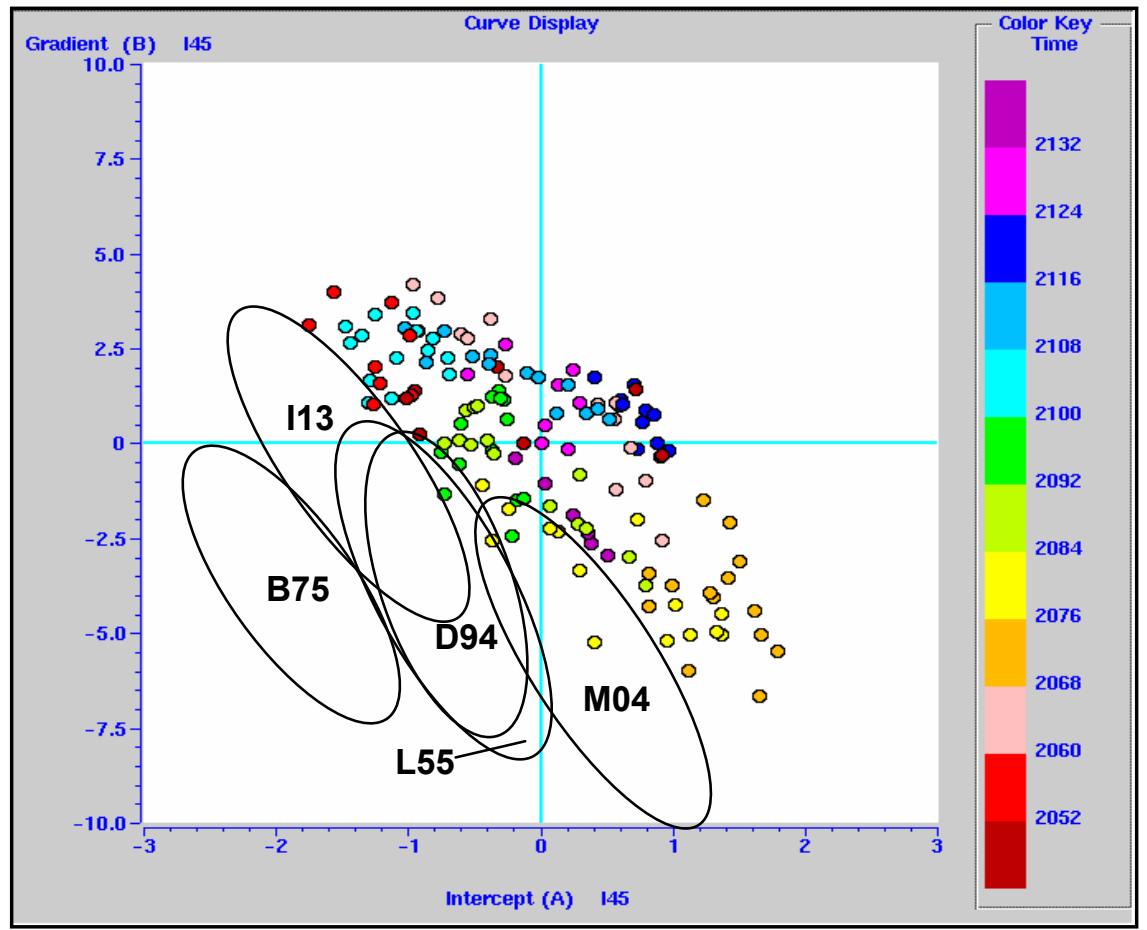

FIG.8. Intercept versus gradient crossplot showing anomalous zones

The B75 well isolates the best; the I13, D94, and L55 wells overlap. This shows a distinct difference between the wells in the D94 block (17-21 API) to the B75 block 
( 28API). The L55 block may not be differentiable using Intercept and Gradient attributes. Since the quality of the L55 block reservoir is degraded the attributes may be only showing the gas cap. This is also supported by the fact that the I45 well does not have a gas cap and does not show a crossplot anomaly.

\section{Fluid factor analysis}

Encouraged by the positive results obtained with the gradient and intercept volumes, P- and S-reflectivity volumes were extracted from the data in order to attain a fluid factor volume. The fluid factor volume is calculated to be low amplitude for all reflectors in a clastic sedimentary sequence except for rocks that lie off the "mudrock line". The "mudrock line" is the trend on a crossplot of $\mathrm{V}_{\mathrm{P}}$ vs. $\mathrm{V}_{\mathrm{S}}$ on which water-saturated sandstones, shales, and siltstones lie. If shear information is not available a global empirical relationship derived by Castagna et al. (1985), called the ARCO mudrock equation, provides $\mathrm{V}_{\mathrm{S}}$. For this data set $\mathrm{P}$-wave and $\mathrm{S}$-wave sonic logs were acquired at the well location. From this log information a local mudrock relationship was derived which was in turn used to create the fluid factor AVO attribute.

A time slice taken through the top of the Ben Nevis zone is shown in Figure 9. Again a distinct AVO anomaly can be seen across the whole asset. The fluid factor volume shows a better, more consistent anomaly across the asset. The bounds of the anomaly are somewhat consistent with, and may represent, the oil-water-contact. An AVO anomaly can be seen down dip in the D94 block.

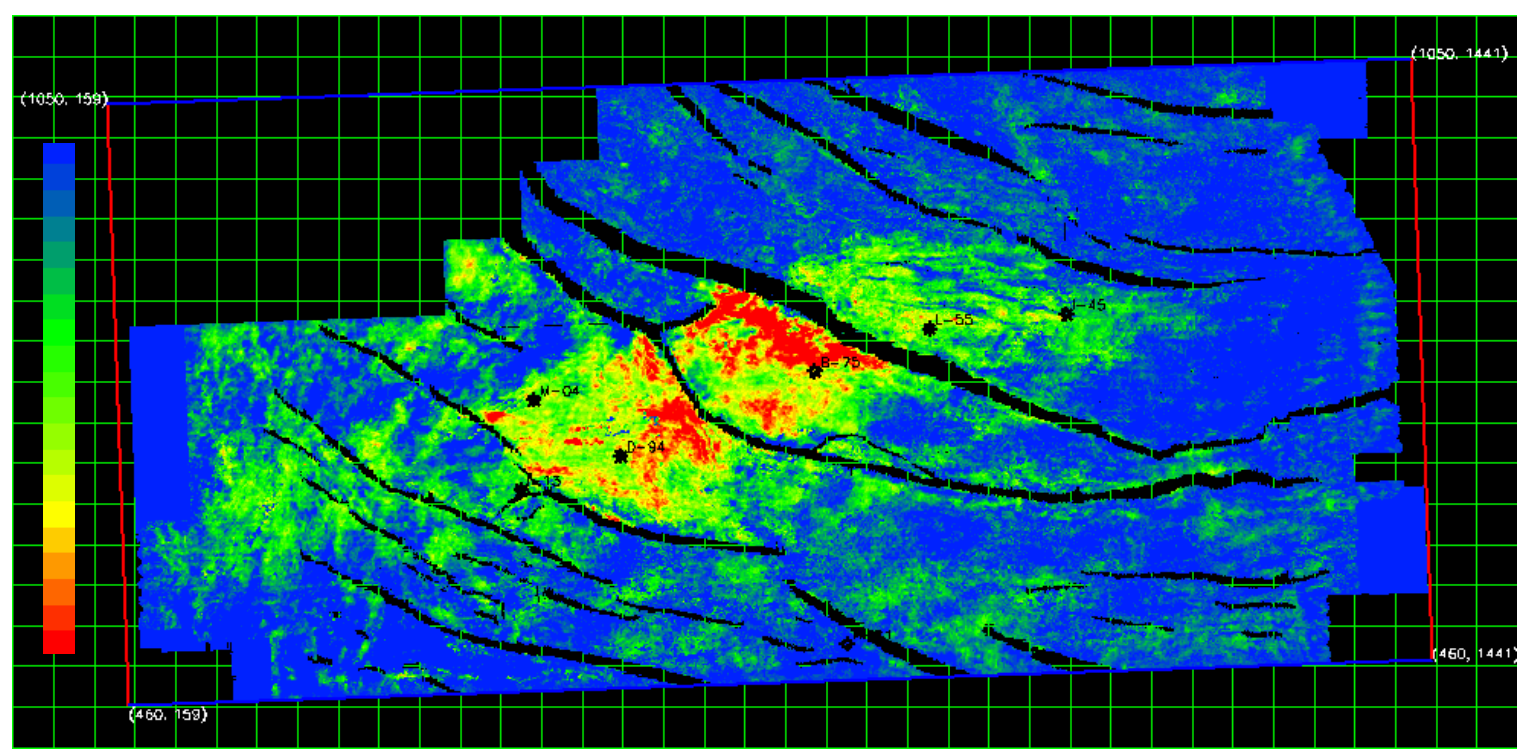

FIG.9. Fluid factor time slice at the top Ben Nevis horizon

Crossplotting of P-reflectivity and S-reflectivity data is undertaken at each well location in an attempt to isolate the nature of the pore fluid. These crossplots are shown in Figure 10. Again, all the wells show isolated anomalous zones, with the exception of the I45 well. A direct comparison is shown in figure 11 with all the anomalous zones plotted on the I45 crossplot. The B75 location separates the best, followed by the other well locations. This maybe indicative of the changing fluid density values in the 
reservoir. The L55 well is indistinguishable from the D94 wells, as seen on the Intercept versus Gradient crossplots. This is most likely due to the reservoir depth and the reservoir conditions compared to the shallower Ben Nevis zones.
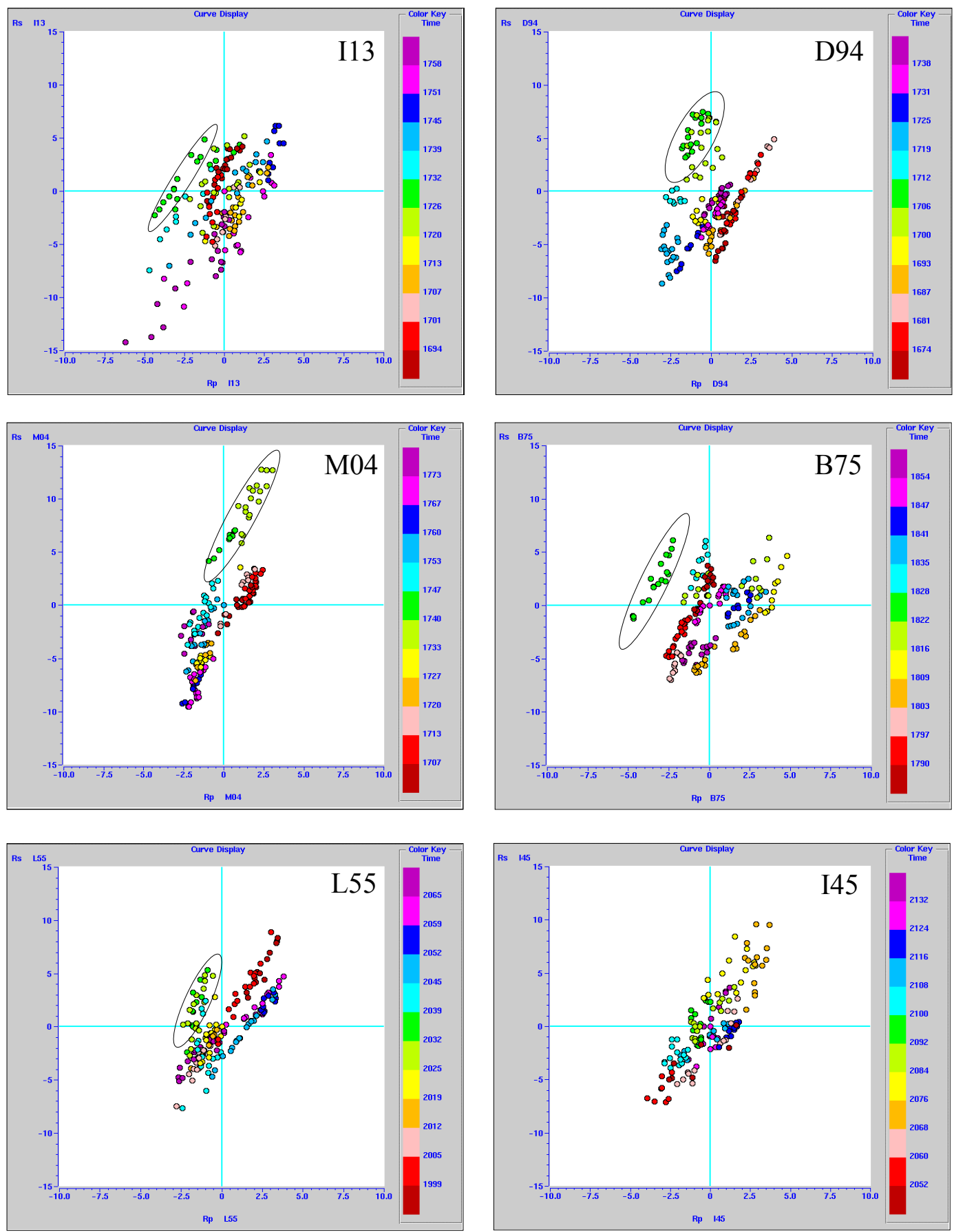

FIG.10. P-reflectivity vs. S-reflectivity (Fluid factor) crossplots at well locations on Hebron asset 


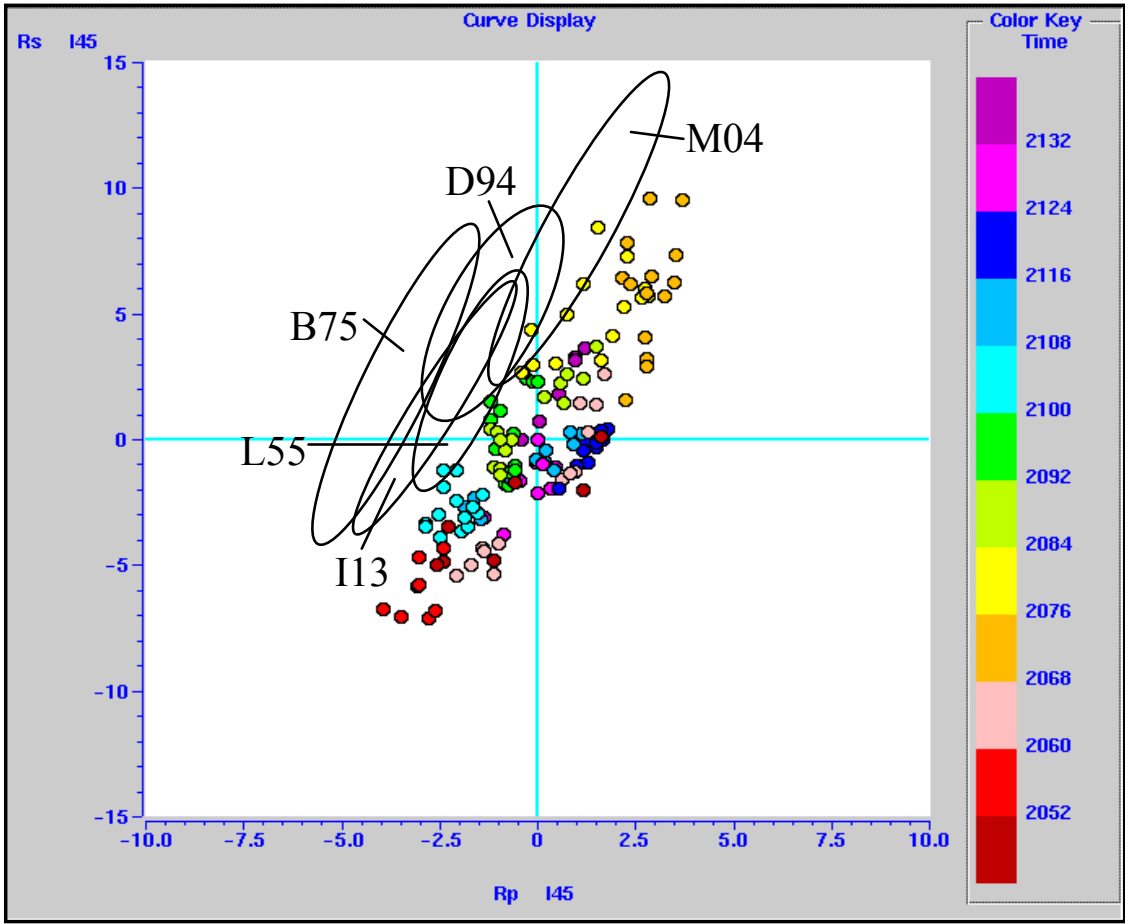

FIG.11. P-reflectivity versus S-reflectivity crossplot showing anomalous zones

\section{Three-term AVO analysis}

A three-parameter AVO extraction was utilized in an attempt to detect density variations for the six volumes. Intercept (A), gradient (B), and curvature (C) are the outputs of this extraction. The intercept and gradient terms should be similar to those extracted from the two-term AVO equation. Once A, B, and $\mathrm{C}$ attributes are acquired, they are arranged to get $\mathrm{P}$-wave velocity reflectivity $\left(\Delta V_{P} / V_{P}\right)$, S-wave velocity reflectivity $\left(\Delta V_{S} / V_{S}\right)$, and density reflectivity $(\Delta \rho / \rho)$. The time slice at the top of the Ben Nevis reservoir of the density reflectivity volume is shown in Figure 12.

The density reflectivity volume shows variations across the asset. The extreme "darks" represents positive variations and the "hots" represent negative variations. The strongest density contrasts are associated with the D94 and B75 blocks. The L55 block shows weak values in comparison. The values in the B75 block are the strongest and again may indicated the presence of lighter gravity oil in comparison to the D94 block. 


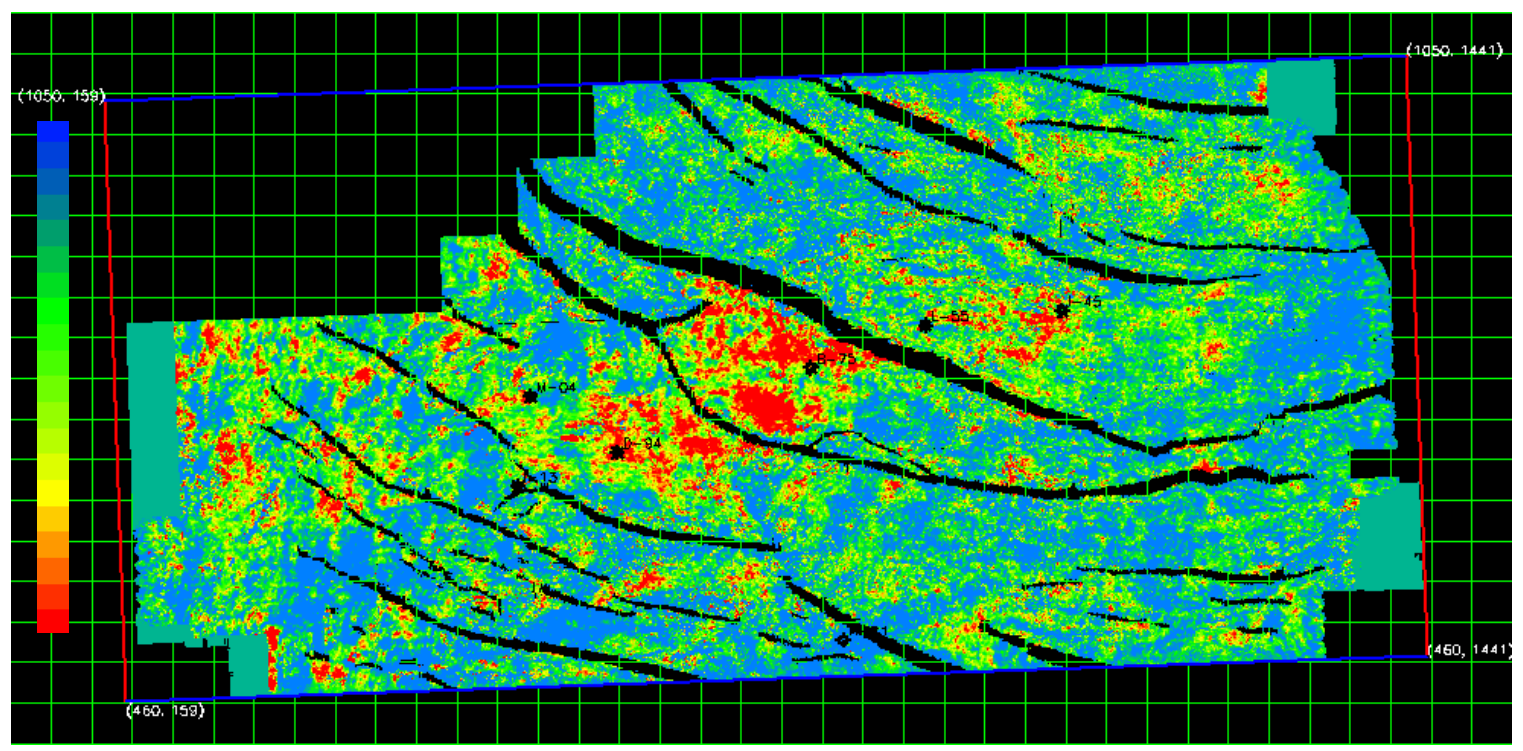

FIG.12. Density reflectivity time slice at the top Ben Nevis horizon

\section{CONCLUSIONS}

In this paper AVO methods were used successfully to distinguish oil density variations at the Ben Nevis oil reservoir. The AVO attribute time slices at the top of the Ben Nevis show the variations across to Hebron asset. The crossplots allow isolation and comparison of the AVO responses at the top of the Ben Nevis zone.

The intercept and gradient analysis isolate the oil bearing zones associated with the Ben Nevis. The gradient volume also shows variations in these oil bearing zones possibly indicating the variations in oil density. The intercept versus gradient crossplots show isolated zones for all the well zones except for the I45 well. In comparison, the B75 location separates out compared to the other locations, isolating the light oil regions. The L55 region is not distinguishable from the D94 block wells.

The fluid factor volume highlights the oil bearing zones across the Ben Nevis zone and may mimic the pool oil-water contact. The B75 block shows the strongest anomalies and also some high values located down dip in the D94 block. The P-reflectivity versus S-reflectivity again isolates all the zones except for the I45 well location. On the comparison plot, the B75 stands out from the other well locations, isolating the lighter oils. The L55 block wells are also not distinguishable compared to the D94 Block wells.

The density reflectivity volume shows anomalies at the Ben Nevis oil zones. The values are strongest at the B75 oil zone in comparison to the D94 and L55 blocks. These variations may be giving information on the varying fluid values across the pool. The L55 block again does not exhibit strong values.

On all the AVO attributes the B75 block, which has an API of $~ 28$, shows the strongest anomalies. Next is the D94 block which has API values ranging from 17-21. The L55 block has API values of approximately 31 with a gas cap in the L55 well and shows a weaker AVO response in comparison. This is most likely due to the degraded reservoir conditions. This reservoir is also approximately 500 meters deeper than the 
other zones. The AVO amplitudes in the L55 block are probably showing anomalies for the gas cap since the L55 well location shows an AVO anomaly and the I45 well location does not.

The AVO anomaly down dip in the D94 block is not expected, but can be possible due to a number of factors. For instance, the lithology of the overlying layer may vary laterally creating a laterally changing impedance boundary. There may be a tuning effect down dip causing the AVO effect to increase. Another scenario is that possibly the down dip fault is not sealed, allowing lighter gravity oil to seep into the block, with the denser oil preventing migration to the up dip portions of the fault block.

\section{FUTURE WORK}

Future work would include inverting for P-wave, S-wave, and density impedance volumes. Also, porosity prediction using neural networks in an attempt to extract a fluid density volume. A $V_{\mathrm{P}} / \mathrm{V}_{\mathrm{S}}$ volume is also to be generated for comparison.

\section{ACKNOWLEDGEMENTS}

We would like to thank Exxon-Mobil, Petro-Canada, ChevronTexaco, and NorskHydro for their work on this field and the release of well data to the public domain. We would like to acknowledge Brian Grant, Craig Coulombe, Paul Gremell, Suzanne Verheyde, Mark MacLeod and Mike Donovan of ChevronTexaco Canada Resources and Gerald Sullivan and Ed Stacey of Petro-Canada. We would like to thank HampsonRussell for the use of their software, especially Brian Russell and Arthur Lee. We also would like to thank the CREWES sponsors and GEO-X Systems Ltd. for their support of this research.

\section{REFERENCES}

Aki, K., and Richards, P. G., 1980, Quantitative seismology: W. H. Freeman \& Co.

Allen, J. L. and Peddy C. P., 1993, 'Amplitude Variation with Offset: Gulf Coast Case Studies', SEG, Tulsa, Oklahoma.

Castagna et al., 1985, Relationships between compressional-wave and shear-wave velocities in clastic silicate rocks: Geophysics, 50, 571-581.

Batzle, M. and Wang, Z., 1992, Seismic properties of pore fluids: Geophysics, 57, 1396-1408.

Downton, J. E., and Lines, L., 2001, Constrained three parameter AVO inversion and uncertainty analysis, CSEG 2001 expanded abstracts.

Fatti, J.L., Smith, G.C., Vail, P.J., Strauss, P.J., Levitt, P.R., 1994 Detection of gas in sandstone reservoirs using AVO analysis: Geophysics, 59, 1362-1376

Kelly, M., Skidmore, C., and Ford, D., 2001, AVO inversion, part 1: Isolating rock properties: The Leading Edge, 20, no. 3, 320-323.

Kelly, M., Skidmore, C., and Ford, D., 2001, AVO inversion, part 2: Isolating rock properties: The Leading Edge, 20, no. 4, 425-428.

Lines, L., 1999, AVO and Density: Canadian Journal of Exploration Geophysics, 35, no. 1/2, 32-35.

Provais, D. A., 2000, Hebron Asset Appraisal - East Coast of Canada Case History, GeoCanada expanded abstracts.

Shuey, R.T., 1985, A simplification of the Zoeppritz equations: Geophysics, 50, 609-614.

Smith, G. C., and Gidlow, P. M., 1987, Weighted stacking for rock property estimation in gas sands: Geophysical Prospecting, 35, 993-1014. 